\title{
The use of donkeys for transport: the case of Khartoum State, Sudan
}

\author{
T.- E. Angara ${ }^{1}$, A. Ibrahim ${ }^{2} \&$ A. Ismail ${ }^{3}$ \\ ${ }^{I}$ College of Animal Production and Technology, \\ Sudan University of Science and Technology, Sudan \\ ${ }^{2}$ College of Veterinary Science, University of Bahr Elgazal, Sudan \\ ${ }^{3}$ College of Veterinary Medicine, \\ Sudan University of Science and Technology, Sudan
}

\begin{abstract}
Although the use of donkeys is considered as backwardness, yet in Khartoum the use of donkey as a means of transport is not uncommon. This paper highlights the importance of donkeys as a means of transport in relation to uneven development in Khartoum. Questionnaire administered interviews and unstructured questionnaires were used in data collection. Researchers' observations were also considered. The study revealed that working donkeys are either pulling carts $(91.1 \%)$, or utilized as pack animals (8.9\%). At the center of the city transport of building and domestic materials is most dominant purpose; as we move to peripheries water and public transports emerge as additional purposes. Most donkey owners (35.9\%) originate from Khartoum State and $35.3 \%$ originate from western Sudan. They are categorized as low income

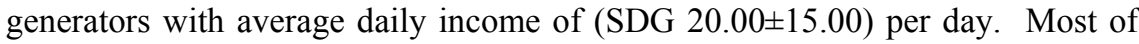
them $(89.3 \%)$ either attended primary education or are illiterate. The paper concluded that the more development the less demand for donkeys in transport. But the situation after the southern Sudan referendum seems to depend more on agriculture and donkeys. The current increment in the transport fees, high prices of fuel and banning the import of second hand vehicles will increase the demand for donkey carts, especially for poor dwellers. Thus, the socio economic factors have their role in determining the means of transport used in urban sites.
\end{abstract}

Keywords: donkey, donkey carts, transport, socio economic, income generation, Khartoum, Sudan. 


\section{Introduction}

\subsection{The use of donkeys for transport}

The donkey (ass) Equus asinus is an important draft animal in many parts of the world. This animal plays an essential role in the economies of underdeveloped countries, Sudan is not an exception. The study of Fielding [1], revealed that donkeys can be used mostly for work namely for transport (riding, pack transport, or pulling carts) or they may be used for farm work and other jobs. He concluded that pack donkeys are a real option for the future as a truly appropriate renewable power source for the tropics.

Other studies in developing countries such as Ethiopia, Kenya, Nigeria and South Africa [2-5], found that donkeys are an essential means of transport to millions of people living below the poverty line and they are often a family's most reliable helper. The economic circumstances have their role in determining the means of transport. In Nigeria, Blench [6], showed that the devaluation of the Naira currency led to an increase in the prices of imported components; therefore, vehicles were difficult to maintain. As a result, many vehicles went out of service and consequently donkeys became popular again especially in rural markets. As reported by Pravda.Ru [7] donkeys become a usual means for transportation in Bethlehem as a result of the military conflict between Palestine and Israel. The results of other studies, [8-10] revealed that in most societies donkeys are often used by women. In northern Tanzania, Swai and Bwanga [11] found the majority of the respondents were of low education level or had no formal education.

\subsection{Sudan development profile}

According to UNDP, IHDI [12], Sudan is considered one of the least developed countries with a Human Development Indicator (HDI) of 0.379, which gives the country a rank of 154 out of 169 countries. As reported in WFB [13], the unemployment rate was estimated at $18.7 \%$ in 2002. In the year 2004 about $40 \%$ of the population were below the poverty line. Sudan's real GDP expanded by $5.2 \%$ during 2010. Robinson et al. [14] mentioned that while the oil sector continues to drive growth, services and utilities play an increasingly important role in the economy and agriculture production remaining important as it employs $80 \%$ of the work force. According to them the currency depreciates considerably before the referendum on southern secession, scheduled in January 2011. The Central Bank of Sudan intervened heavily in the currency market and the Sudanese government introduced a number of measures to restrain excess local demand for hard currency.

\subsection{Donkeys in Sudan}

Sudan possesses a large and diversified animal wealth consisting of domesticated animals and wild life [15]. Equines are mainly horses which accounts for 784.5 
thousand and approximately 7,5 million head of donkeys as shown in table 1 and fig.1. No data on mules is available.

Located in North east Africa, Sudan was identified as the origin of the Nubian wild ass Beja-Pereira et al. [16] where it has been domesticated and used for different purposes. Ali et al. [17] mentioned that despite the increase in industrialization, donkeys are still in wide use in rural and urban sites of Sudan. They are becoming increasingly important animals given the new socioeconomic situation with an increased use of donkeys instead of horses in labour. The present work investigates the use of donkeys for transport in Khartoum state in relation to the socioeconomic characteristic of their owners.

Table 1: $\quad$ Distribution of donkey population in Sudan by region.

\begin{tabular}{|c|c|c|c|c|c|c|}
\hline Region & Western & Central & Eastern & Northern & Southern & Total \\
\hline Number & $4,073,225$ & $1,953,217$ & $1,119,761$ & 360,728 & 15,030 & $7,521,961$ \\
\hline$\%$ & 54.15 & 25.96 & 14.89 & 4.80 & 0.20 & 100.00 \\
\hline
\end{tabular}

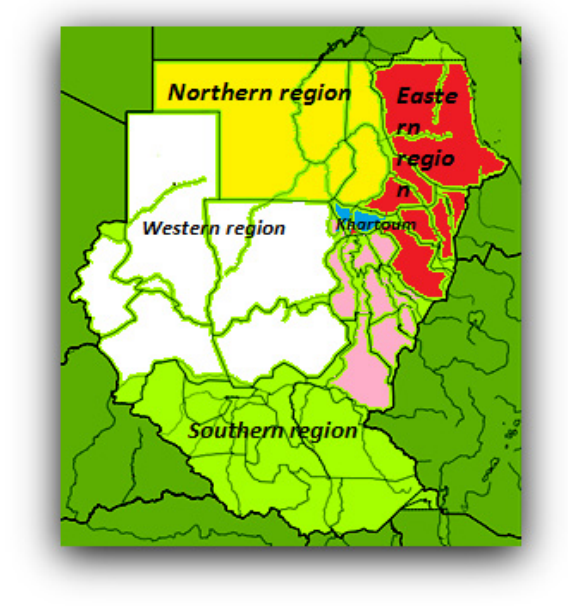

Figure 1: $\quad$ Regions of Sudan.

\section{Material and methods}

\subsection{Study area}

Lying in a semi desert region, Khartoum State is divided by the white, blue and the main River Nile into three urban districts namely Khartoum, Khartoum North and Omdurman, beside a vast rural area. The state was subjected to different migratory impulses through history from different parts of Sudan and for a variety of reasons including the civil war, drought in 1983, or for seeking job opportunities. Most of them inhabit the peripheries of the three towns. 


\subsection{Study population and data collection}

A total of 203 donkey drawn carts drivers in eight administrative units in the three districts were purposely selected using a quota sample. Of these, 108 from Omdurman (Salha, Gundahar, Abuzead and Gamair), 54 from Khartoum (Mayo and Kalakla) and 41 from Khartoum North (Hillat-Kuku and Shigla). They were either visited at their working points or when they come to consult some selected veterinary centers. The data was collected during the year 2009-2010. Questionnaire administered interviews were used in data collection. Researchers' observations were also considered. Further in depth investigation was also undertaken for those who use donkey carts for public transport. Personal interviews with cart drivers and utilizers were done. Veterinarians, local administrative officers, resource persons were also interviewed using unstructured questionnaires.

\subsection{Statistical analyses}

Collected data sets were entered, managed and analysed using SPSS Version 16. Descriptive statistics generated included counts, frequencies and means.

\section{Results}

\subsection{The uses of donkeys in Khartoum State}

Donkeys were used either as pack animals (8.9\%) or most dominantly for pulling carts $(91.1 \%)$. One basic design of carts which can be modified to fit the different purposes was observed; all of the carts have two shafts and use only one donkey. Carts with platform surface can be used for multi purposes. Carts with wooden or metal boxes mainly for bread transport. Carts with two metal barrels attached together for water transport and special design for milk containers as shown in figs. 2-7.

As presented in table 2 about $12.8 \%$ of the donkeys and donkey drawn carts were owned to provide personal services whether in domestic affairs or to help the owner in running his own business. A dairy farmer may keep a donkey or

Table 2: $\quad$ The different donkey transport purposes in Khartoum State.

\begin{tabular}{|l|c|c|}
\hline Transport purposes & Frequency & Percent \\
\hline Personal use & $\mathbf{2 6}$ & $\mathbf{1 2 . 8}$ \\
\hline Income generation & $\mathbf{1 7 7}$ & $\mathbf{8 7 . 2}$ \\
Transport of building materials & 34 & 16.7 \\
Transport of farm produce & 31 & 15.3 \\
Transport of water & 31 & 15.3 \\
Transport of consumer goods & 25 & 12.3 \\
Public transport & 24 & 11.8 \\
Transport of milk & 7 & 3.5 \\
Other transport purposes & 25 & 12.3 \\
\hline Total & $\mathbf{2 0 3}$ & $\mathbf{1 0 0 . 0}$ \\
\hline
\end{tabular}


donkey draught cart for farm work to transport animal feed, water or distribution of milk. A trader may also keep a donkey to assist him to transport goods.

Donkeys in Khartoum state are mainly used for income generation (87.2\%). About $79.8 \%$ of them were specialized in one purpose, while $20.2 \%$ were used as a multipurpose means of transport. Transport of building materials was the most common purpose in which donkey carts were used all over the state. Flat surface carts are mostly used for transportation of cement, iron sheets, etc. (fig. 2), whereas the sand is transferred using flat surface cart or cart with metal boxes. Donkeys play an important role in transportation of farm products other than milk such as vegetables and fruits either from farm to markets or from central vegetable markets to retailing centers. Women were observed to be involved in selling vegetables using donkey cart for transport. A donkey pulling a cart with two barrels attached together (fig. 3) was a usual phenomenon in areas deprived of the water network. They also solve the problem when there is a shortage in tap water supply during the dry season. Besides supplying domestic houses they also supply the dairy farms and provide water for building construction. All over the state donkey carts were used vis a vis other means of transport to carry consumer goods at different levels of the marketing channel. So we can find donkey carts at central markets, wholesale markets and retailing centers (fig. 4). Traditionally, milk is transported on the back of donkeys, a small milk container at each side. Urbanization and increased population implies the use of donkey carts vegetables, fruit, milk or sometimes domestic equipment or act as mobile welding workshops (fig. 6).

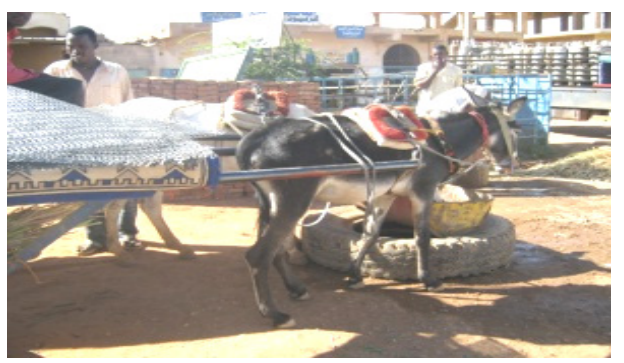

Figure 2: $\quad$ Transport of building materials.

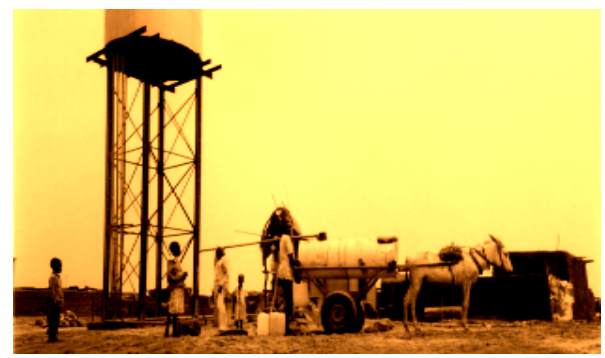

Figure 3: Water transport. 


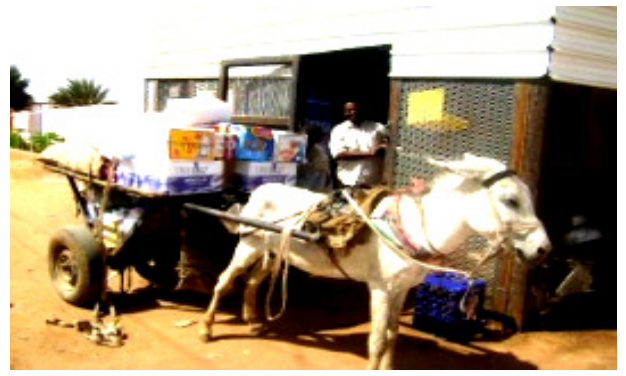

Figure 4: $\quad$ Transport of consumer goods.

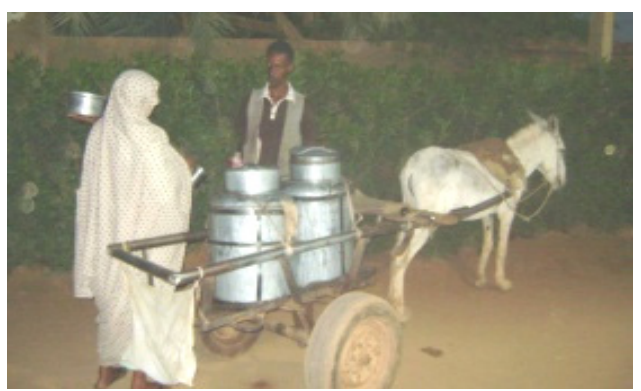

Figure 5: $\quad$ Transport and selling milk.

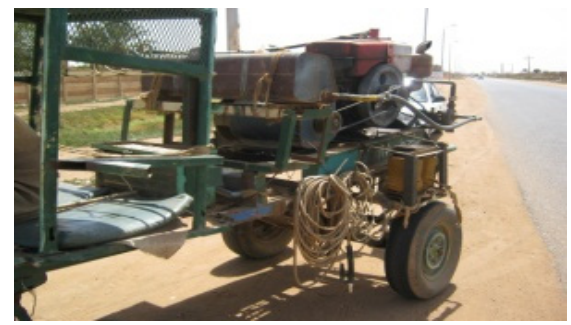

Figure 6: Welding workshops.

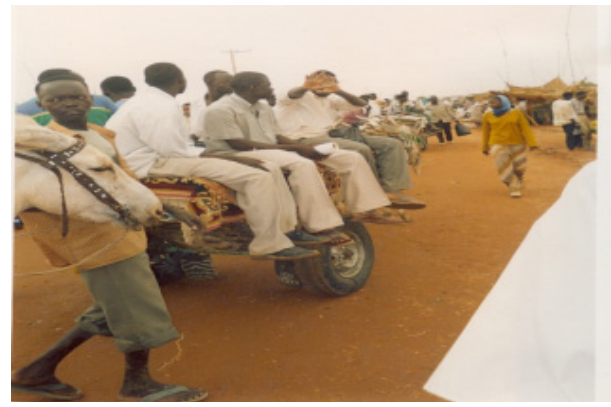

Figure 7: Public transport. 


\subsection{The socio economic aspect of donkey uses in Khartoum state}

The study revealed that almost all of the donkey owners are male (99.5\%). Their age varies largely between 12 and 70 years with an average of $34.3 \pm 11.3$ years. Child labour was encountered in this study. A low education level predominates among the owners with primary education being the highest followed by illiteracy; together they constitute $89.3 \%$ of donkey owners. Three university graduates account for $1.3 \%$ among the donkey owners. In depth investigation in the use of donkey carts as public transport (fig. 7), revealed that almost all the users originate from western and southern regions and inhabit the peripheries. Both sexes at different ages use donkey carts. The daily income generated by using donkeys was found to range between SDG 4.00 and 80.00 with the most frequent income being SDG 15.

\section{Discussion}

In the present study the use of a donkey as a pack animal in Khartoum State is significantly lower $(\mathrm{P}<0.05)$ than for pulling carts. This is in agreement with the results of Honekom [3] in South Africa. The use of pack donkeys in Khartoum North is significantly higher than the other two districts. This may be attributed to the fact that Khartoum North is less populated than the other two districts in which there was more need for heavy loads justifying the more use of pulling carts than loading the animal. In Khartoum State the donkey cart was pulled by one donkey while in South Africa the most common case is the double donkey cart as described by Honekom [3]. In this study, almost all the donkey owners are men; a similar observation was reported by SOS [18] in several Sahilian countries. The gender difference in ownership and access to using a donkey varies according to cultures, urban - rural variation does occur. The conception of donkey ownership as backwardness stems from the fact that urban women do not use or own donkeys, in contrast to women in rural areas especially in the absence of husband as in the case of western Sudan and Northern Ethiopia [19, 20]. The education level of the donkey owners in Khartoum state is similar to that reported by Swai and Bwanga [11] in Tanzania. However, few university graduates and children were encountered in Khartoum State among the donkey owners. The different purposes for using donkeys for transport in this study is similar to that recorded in several African countries [2-5]. The role of donkeys in the urbanization process in Khartoum State cannot be overseen. All over the state, no single building material shop without a donkey drawn cart waiting beside. Moreover, a special parking place was devoted to donkey carts in Sajana market at the center of Khartoum town. They are cheaper and at disposal. As we move away from the center, donkeys contribute to solving the problems of underdevelopment where water needs to be carried from wells to the domestic households. Unconstructed roads in the peripheries of Khartoum State provide a good chance for donkey carts as a means of transport. A similar result was obtained by Mukiria et al. [5] in the case of Lamu archipelago, Kenya. This is also applied to public transport where the three wheel car "Reksha" constitutes a 
very strong competitor. However, in the periphery donkey carts are preferred because they are cheaper. In addition to providing such services donkeys carts constitute a source of income generation to a good number of families in these parts of Khartoum state. The daily income generated by using donkeys indicates that operating a business using a donkey is more profitable than some jobs in public or private sectors in Sudan. The case resembles that in Addis Ababa where the minimum monthly net income of a Donkey Pack Transport Operations (Birr 125) in 1997 was higher than the minimum salary of a civil servant (Birr 105) as reported by Sisay and Tilahun [2]. The average annual income generated by using donkeys in Khartoum State is much higher than the highest income generated in Makete, Tanzania which ranged between US\$ 55 and US\$ 124 per household based on Sieber [21]. If we consider an average number of households of 6.1, and an exchange rate of $\$ 1=$ SDG 2.5 in 2009, then we will end with $\$ 3.3$ a day per person compared with the poverty line of $\$ 1$ a day per person. The use of donkeys in Khartoum support owners, utilizers as well as the state government. Donkey owners directly pay for licenses and different taxes such as waste tax every year. Moreover, before issuing the license the donkey should be examined by a veterinarian and in the case of water and milk transportation, the operators should also be subjected to medical examination. These also add to the state government expenditure.

\section{Conclusion}

The paper concludes that although the use of donkeys is considered as a sign of backwardness and underdevelopment, yet in Khartoum State donkeys contribute in the process of urbanization besides solving the problems of marginalizing people by providing necessary transport services. They act as a source of income mostly for low level education people regardless of their ethnic origin and age. Thus, donkeys act to alleviate poverty and create job opportunities.

\section{Acknowledgements}

This study was supported by a grant from the Ministry of Higher Education and Scientific Research. Providing sincere effort in data collection, the authors are indebted to all who participated in completion of this work: donkey owners, resource persons and data collectors, many thanks are extended to all of them.

\section{References}

[1] Fielding, D., Pack Transport with Donkeys. Appropriate Technology Journal Volume (15) pp.11-13. 1988. http://practicalaction.org /practicalanswers/product_info.php?products_id $=213$

[2] Sisay, Z., \& Tilahun F., The role of donkey pack-transport in the major grain market of Addis Ababa (paper). Donkeys, people and development, eds. P. Starkey and D. Fielding. A resource book of the Animal Traction 
Network for Eastern and Southern Africa (ATNESA). ACP-EU Technical Centre for Agricultural and Rural Cooperation (CTA), Wageningen, The Netherlands. pp.71-78. 2000. Paper available from http://www.atnesa.org

[3] Hanekom, D., The use of donkeys for transport in South Africa (Paper). Donkeys, people and development. eds,. P. Starkey and D. A. Fielding. A resource book of the Animal Traction Network for Eastern and Southern Africa (ATNESA). ACP-EU Technical Centre for Agricultural and Rural Cooperation (CTA), Wageningen, The Netherlands. 244p. ISBN 92-9081219-2. 2000.

[4] Blench, R; de Jode, A \& Gherzi, E., Donkeys in Nigeria: history, distribution and productivity (Paper). Donkeys, people and development (resource book of the Animal Traction Network for Eastern and Southern Africa (ATNESA), eds,. P. Starkey and D A Fielding. ACP-EU Technical Centre for Agricultural and Rural Cooperation (CTA), Wageningen, The Netherlands. pp. 210-219. 2000. Available at http://www.atnesa.org

[5] Mukiria, P., Mdachi R., Thuita, J., Mutuku, J., Wanjala, K., Omolo, J., Mulugeta, G., Trawford, A., Ouma1, J., \& Murilla, G., Semi-longitudinal study of trypanosomiasis and its vectors in donkeys Proceedings of the 12 th kARI Biennial Scientific Conference. 2010.

[6] Blench R. A., history of domestic animals in Northeastern Nigeria -Cah. Sci hum. 31 (II): pp. 181-237, 1995.

[7] Pravda. Ru. Donkeys Are a Better Transport. Online: http://english.pravda.ru/news/society/sex/24-12-2002/19663-0/2

[8] Mutharia, L., Oloyiankalani Group Ranch: a participatory assessment of pastoral resources and their utilisation in selected areas of Kajiado District. Intermediate Technology Kenya, P. O. Box 39493, Nairobi, Kenya. 71 p. 1995.

[9] Starkey, P., \& Starkey, M., Regional and world trends in donkey populations (paper). Donkeys, people and development, eds. P. Starkey and D. Fielding A resource book of the Animal Traction Network for Eastern and Southern Africa (ATNESA). ACP-EU Technical Centre for Agricultural and Rural Cooperation (CTA), Wageningen, The Netherlands. ISBN 92-9081-219-2. pp. 10-21. 2000. Paper available from http://www.atnesa.org

[10] Bwalya, M., Extension staff and farmer training challenges in donkey traction applications (Paper). Donkeys, people and development. eds,. P. Starkey and D A Fielding (resource book of the Animal Traction Network for Eastern and Southern Africa (ATNESA),ACP-EU Technical Centre for Agricultural and Rural Cooperation (CTA), Wageningen, The Netherlands. pp. 134-136. 2000.

[11] Swai, E. S. \& Bwanga, S. J. R., Donkey keeping in northern Tanzania: socio-economic roles and reported husbandry and health constraints. Livestock Research for Rural Development. (20), Article \#67. 2008. Retrieved March 30, 2011, from http://www.lrrd.org/lrrd20/5 /swai20067.htm 
[12] UNDP, IHDI http://hdrstats.undp.org/en/countries/profiles/SDN.html. 2010 http://hdrstats.undp.org/en/countries/profiles/SDN.html

[13] World Fact Book WFB, http://www.theodora.com/wfbcurrent/sudan/ sudan_economy.html 2011

[14] Robinson, M., Held, D., Santos, S., Onuma, Y., An-Na'Im A., Population below poverty line http://www.theodora.com/wfbcurrent/sudan/sudan economy.html Academy of Human Rights 2001. Page last updated on January 12, 2011.

[15] Ministry of Animal Resources and Fisheries MARF: Annual Report. 2009.

[16] Beja-Pereira Albano, Phillip R. England, Nuno Ferrand, Steve Jordan, Amel O. Bakhiet, Mohammed A. Abdalla, Marjan Mashkour, Jordi Jordana, Pierre Taberlet, Gordon Luikart. African Origins of the Domestic Donkey Science 18: Vol. 304. (5678): 1781. 2004.

[17] Ali, T. M. O., Ibrahim, K. E. E., Eltom, E. H. A.\& Hamid, M. E., Animal diseases diagnosed at the University of Khartoum Veterinary Teaching Hospital (1995-1998). Sud. J. Vet. Sci. Anim. Husb. (40) 38-44. 2001.

[18] SOS. Changing Places? Women, resource management and migration in the Sahel. SOS Sahel UK, Tolpuddle Street, London N1 0XT, UK. 169 p 1995.

[19] Abu Sin, M. A., \& Hadra, T. O., ITDGs to the Kbekabeiya small holders project: an evaluation, Intermediate Technology Sudan P.O. Box 4172 Khartoum and Intermediate Technology, Myson House, Railway terrace, Rugby CV 21 3HT, UK. 1994.

[20] Marshal, K., Ali, Z., \& Terfa, B., Socioeconomic issues of donkey use in Ethiopia; A case study of changing relationship. Paper prepared for (ATNESA). Workshop, on improving donkey utilization and management Debre Zeit, Ethiopia 5-9 May 1997.

[21] Sieber, N., The economic impact of pack donkeys in Makete, Tanzania. Donkeys, people and development, eds. P. Starkey and D. Fielding. A resource book of the Animal Traction Network for Eastern and Southern Africa (ATNESA). ACP-EU Technical Centre for Agricultural and Rural Cooperation (CTA), Wageningen, The Netherlands. pp. 120-123, 2000. Paper available from http://www.atnesa.org 